\title{
Novel EYA4 variant in Slovak family with late onset autosomal dominant hearing loss: a case report
}

\author{
Lukas Varga ${ }^{1,2}$, Daniel Danis², Martina Skopkova², Ivica Masindova², Zuzana Slobodova ${ }^{1,2}$, Lucia Demesova',
} Milan Profant ${ }^{1}$ and Daniela Gasperikova ${ }^{2 *}$ (D)

\begin{abstract}
Background: Progressive bilateral sensorineural deafness in postlingual period may be linked to many different etiologies including genetic factors. Identification of the exact deafness cause may, therefore, be quite challenging. Here we present a family with late-onset hearing loss as an autosomal dominant trait caused by a novel EYA4 mutation.

Case presentation: Forty-four years old female proband clinically investigated for progressive hearing loss and occasional dizziness with positive family history for deafness was subject to molecular-genetic testing. Patient's DNA sample was analyzed by whole exome sequencing. We identified a novel missense variant c.804G >C located at the last base pair of exon 10 in EYA4. Candidate variant was confirmed by Sanger sequencing in the proband and her family members. In silico prediction tools and co-segregation analysis were used to indicate pathogenicity of the identified variant. To confirm our hypothesis, we performed minigene assay to demonstrate if the transcript of exon 10 in EYA4 is present. We provide evidence that this mutation in vitro compromises donor site functionality and causes exon 10 skipping and frameshift that most likely results in nonsense-mediated mRNA decay. The onset of moderate to severe hearing loss in the family ranged from 10 to 40 years. The normal cardiac phenotype was confirmed by ECG and echocardiography.

Conclusions: We identified a novel EYA4 mutation associated with adult-onset autosomal dominant sensorineural hearing loss. This report extends the knowledge of spectrum of EYA4 mutations and demonstrates the pathogenicity of a variant affecting specific position in the gene. A comprehensive review of known EYA4 mutations is also given and their impact on cardiac phenotype is discussed. Our findings highlight the importance of genetic testing and complex clinical assessment in patients with familial progressive hearing loss.
\end{abstract}

Keywords: Sensorineural deafness, Postlingual, Next-generation sequencing, Autosomal dominant

\section{Background}

Autosomal dominant sensorineural hearing loss (ADSNHL) accounts for about $20 \%$ of all hereditary nonsyndromic SNHL cases. Currently, at least 38 genes are known to be associated with nonsyndromic ADSNHL [1]. In contrast to the autosomal recessive SNHL, which is typically congenital or prelingual, the onset of ADSNHL is often delayed and escapes the neonatal hearing screening. It may develop as late as in adulthood and it may even overlap with

\footnotetext{
* Correspondence: daniela.gasperikova@savba.sk

${ }^{2}$ Diabgene Laboratory, Biomedical Research Center, University Science Park

for Biomedicine, Slovak Academy of Sciences, Bratislava, Slovakia

Full list of author information is available at the end of the article
}

presbycusis $[2,3]$. Therefore, genetic etiology may not raise sufficient awareness in the diagnostic workup. The course of hearing loss in ADSNHL is generally progressive, although the speed of hearing deterioration and its severity may vary among different genes or even among different affected individuals. More importantly, progressive bilateral SNHL is often the first symptom in a number of syndromic forms of hearing loss [4].

One of these genes is EYA4 (Eyes Absent Homolog 4) which encodes a 640-amino-acid protein that serves as a transcription coactivator. In higher animals EYA4 is a component of network composed of genes belonging to the Pax, Six, Eya, and Dach families which play a key

(c) The Author(s). 2019 Open Access This article is distributed under the terms of the Creative Commons Attribution 4.0 International License (http://creativecommons.org/licenses/by/4.0/), which permits unrestricted use, distribution, and reproduction in any medium, provided you give appropriate credit to the original author(s) and the source, provide a link to the Creative Commons license, and indicate if changes were made. The Creative Commons Public Domain Dedication waiver (http://creativecommons.org/publicdomain/zero/1.0/) applies to the data made available in this article, unless otherwise stated. 
regulatory role in the development of multiple organs including the eye, muscle, ears, heart, lungs, endocrine glands, placodes, pharyngeal pouches, craniofacial skeleton, and parathyroid [5]. This protein contains a highly conserved 271 amino acid Eya domain (eya homologous region, eya-HR) at the C-terminus and a poorly conserved proline-serine-threonine (PST)-rich transactivation domain called variable region (eya-VR) at the N-terminus [6]. It has been proposed that truncations of the C-terminal Eya domain cause nonsyndromic ADSNHL (DFNA10) whereas upstream truncations deleting the $\mathrm{N}$-terminal variable region cause hearing loss with dilation cardiomyopathy [7]. To date, there are only a few reported families in who ADSNHL segregated with EYA4 mutations.

Here we present a Slovak pedigree with late-onset progressive SNHL analyzed by whole exome sequencing (WES), which allowed us to identify a novel pathogenic variant in the EYA4 gene.

\section{Case presentation}

\section{Diagnostic assessment}

\section{Family and clinical evaluation}

Forty-four-year-old Caucasian female proband suffering from progressive bilateral SNHL since the second decade of her life and positive family history for hearing loss was referred to the Department of ORL-HNS at the University Hospital in Bratislava. Detailed family history questioning revealed other five affected family members in three generations with autosomal dominant inheritance pattern. After excluding the DFNB1 etiology in the proband as a routine step in our diagnostic pipeline for hereditary hearing loss, peripheral blood was taken for DNA analysis and general ENT examination together with audiological tests (tympanometry, stapedial reflexes, ABR, pure tone audiometry in frequency range $250-6000$ $\mathrm{Hz}$ ) were performed in all affected and unaffected family members, who agreed to participate. Additionally, the affected individuals were also subject to vestibular examination (VEMPs, video Head Impulse Test, videonystagmography, caloric testing, and postural tests) to evaluate the vestibular function of the inner ear. Moreover, the proband underwent imaging studies (temporal bone CT and MRI).

After WES results were obtained and hearing loss etiology was determined, three affected subjects older than 40 years underwent detailed cardiological assessment including ECG and echocardiography. All participants or their legal representatives signed informed consent and the study was approved by the Ethics Committee of University Hospital in Bratislava.

\section{Whole exome sequencing}

Genomic DNA was isolated from peripheral blood using standard procedures. WES was done by a service provider (BGI, HongKong). DNA library was prepared using BGI 59 M Human Exome kit and was sequenced on Complete Genomics Black Bird platform (BGI, Shenzen, China).

Sequencing data was processed by BGI's standard bioinformatics pipeline which encompassed base calling, alignment of generated reads to the GRCh37 reference genome without the unplaced or alternate loci and variant calling. Aligned reads and called variants were obtained in standard bioinformatics formats and subjected to following bioinformatics pipeline. Variants were decomposed and normalized using vt [8]. Variant effect predictor [9] was used to annotate the variants with respect to their potential effects on genes and transcripts and to add scores from in-silico prediction algorithms PolyPhen and SIFT. As the last step of variant annotation, the Gemini framework [10] was used to insert variants into newly created SQLite database and to add additional data from genome annotation databases like dbSNP [11], ENCODE [12], ClinVar, 1000 Genomes [13], Exome Sequencing Project (ESP) [14] and Exome Aggregation Consortium (ExAC) [15].

Then, variant prioritization and filtering were realized by removing those with a MAF $\geq 0.01$ (based on $\mathrm{dbSNP}$ v138, ESP, ExAC v0.3) and the resulting variant set was further narrowed down by removing variants not lying inside regions of 91 genes with known association with nonsyndromic sensorineural hearing loss (NSNHL) in human. Set of evaluated NSNHL genes was based on the Hereditary Hearing Loss webpage [1].

\section{In silico analysis}

Functional consequences of candidate variants were evaluated using CADD, PolyPhen and SIFT prediction algorithms [16-18]. The strength of $w t$ and mutated splice donor site was assessed using MaxEntScan, Human Splicing Finder and NNSplice [19-21].

\section{Sanger sequencing}

Sanger sequencing was performed to verify variants identified by WES and to determine co-segregation of the candidate variant with hearing loss in all participating family members. PCR primers amplifying exon 10 and $100 \mathrm{bp}$ of surrounding intronic regions of EYA4 were designed using Primer BLAST software. Sequencing reactions of PCR products were carried out using BigDye Terminator v3.1 chemistry and separated on ABI 3500 genetic analyzer (Applied Biosystems) according to manufacturer's instructions. GenBank RefSeq NM_004100.4 was used as the EYA4 reference sequence.

\section{Minigene assay}

Minigene assay was performed as described in [22]. The pSpliceExpress vector was a gift from Stefan Stamm 
(Addgene plasmid \# 32485). Briefly, EYA4 exon10 was amplified from patient DNA using primers with attB1 and attB2 tails and was cloned into the pSpliceExpress using Clonase BP (Invitrogen). Competent cells (SIG10 $5 \alpha$, Sigma) were transformed and positive clones were selected on ampicillin $(100 \mathrm{mg} / \mathrm{ml})$. The sequence of selected clones was verified using colony PCR and sequencing. Purified plasmids from two clones, one wild type and one carrying tested mutation, were used for lipofection of HeLa (Sigma) cells. Cells were lysed after $24 \mathrm{~h}$, RNA was extracted with DNaseI step included, reverse transcribed, the minigene cDNA was amplified, and presence/absence of EYA4 exon10 was tested on agarose gel electrophoresis and verified by sequencing. Quantification of band densities was carried out with ImageJ [23] and counted ratio was corrected for the molecular weight of compared fragments.

\section{Clinical findings}

The pedigree of the family presenting with autosomal dominant NSNHL is shown in Fig. 1. In total, 8 affected individuals in 4 generations could be identified presenting with postlingual bilateral progressive sensorineural hearing loss. From 12 individuals available for genetic and audiological testing we identified 6 subjects with bilateral sensorineural hearing loss corresponding to the phenotype of the proband. In female subject III:9 this was the primary diagnosis of hearing loss, as she was not aware of any major subjective hearing problems yet. The degree of hearing loss in the affected subjects ranged from moderate to severe hearing loss based on pure tone average at frequencies 500, 1000, 2000 and $4000 \mathrm{~Hz}$ (Fig. 2). Moreover, one subject (III:5) demonstrated unilateral SNHL. The age of hearing loss onset varied between 10 and 40 years and had a progressive course in all subjects based on serial audiograms. One mutation carrier (IV:1) had yet normal pure tone thresholds at the age of 21 years. Construction of age-related typical audiogram (ARTA) showed the most rapid hearing deterioration in the 5th and 6th decade of life (Fig. 3). All subjects requiring hearing rehabilitation benefited from conventional hearing aids. Tinnitus was inconstantly present in 3 subjects, without any association to age or hearing loss severity. Vestibular symptoms (vertigo with occasional headache) only occurred in the proband. Based on the clinical history and results of vestibular testing we supposed the diagnosis of vestibular migraine independently from the etiology of hearing loss. Temporal bone anatomy in the proband was normal based on CT and MRI scans.

Cardiologic findings demonstrated normal heart morphology and function in all three investigated subjects (II:2, II:6, III:2), without any signs of dilation cardiomyopathy. Similarly, no history of sudden cardiac death or increased prevalence of cardiac disease was recorded in the family. Additional clinical findings, which were only present in the mutation carriers, but did not clearly cosegregate with the mutation included blindness in subject II:10 due to bilateral retinopathy with onset in childhood.

\section{DNA analysis results}

Whole exome sequencing was performed in the proband (III:2). In total, 558 million uniquely mapped reads with MAPQ $\geq 30$ were generated, covering $93.45 \%$ of exome target regions at least 20x. The overall mean sequencing depth was $162.22 x$ (Table 1). A total of 46,457 variants were called, transition vs. transversion ratio and values

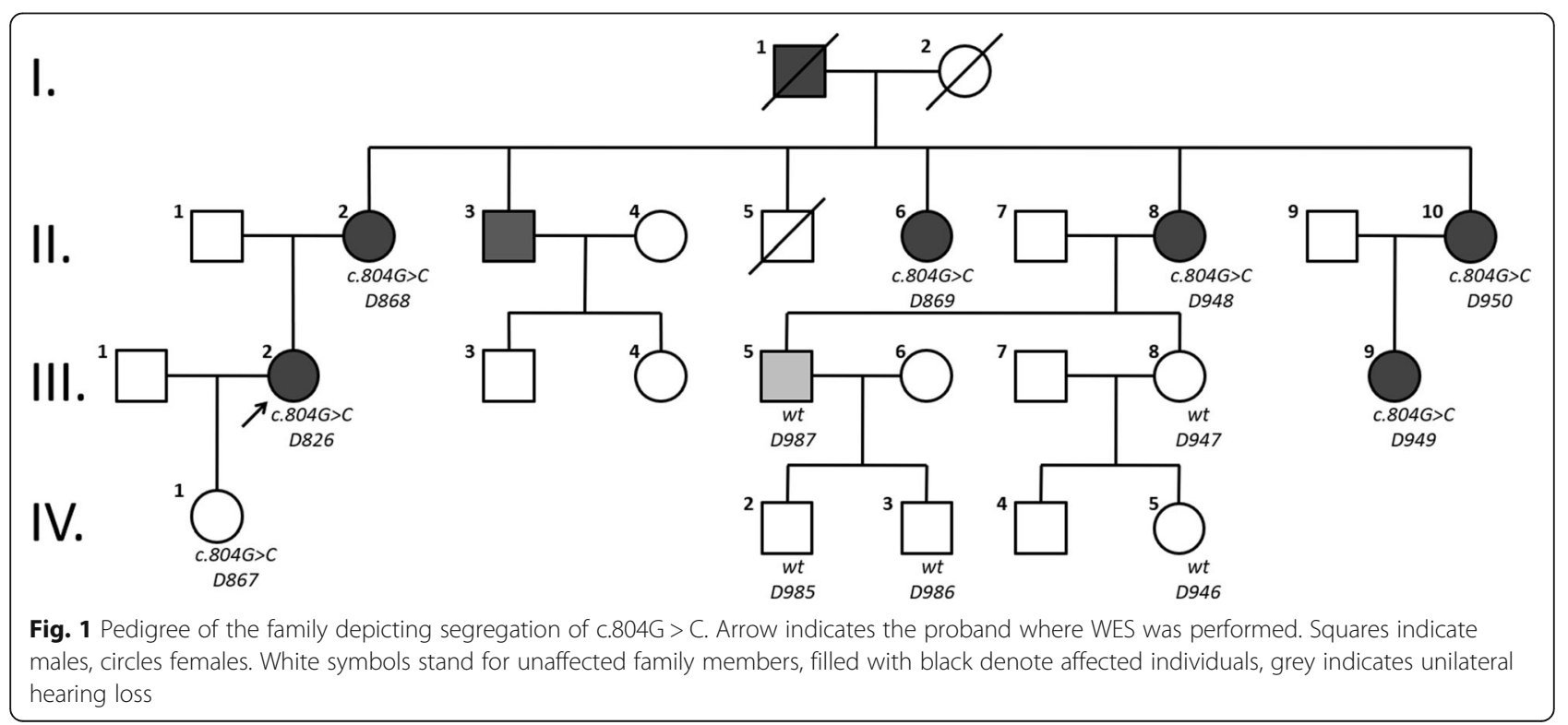




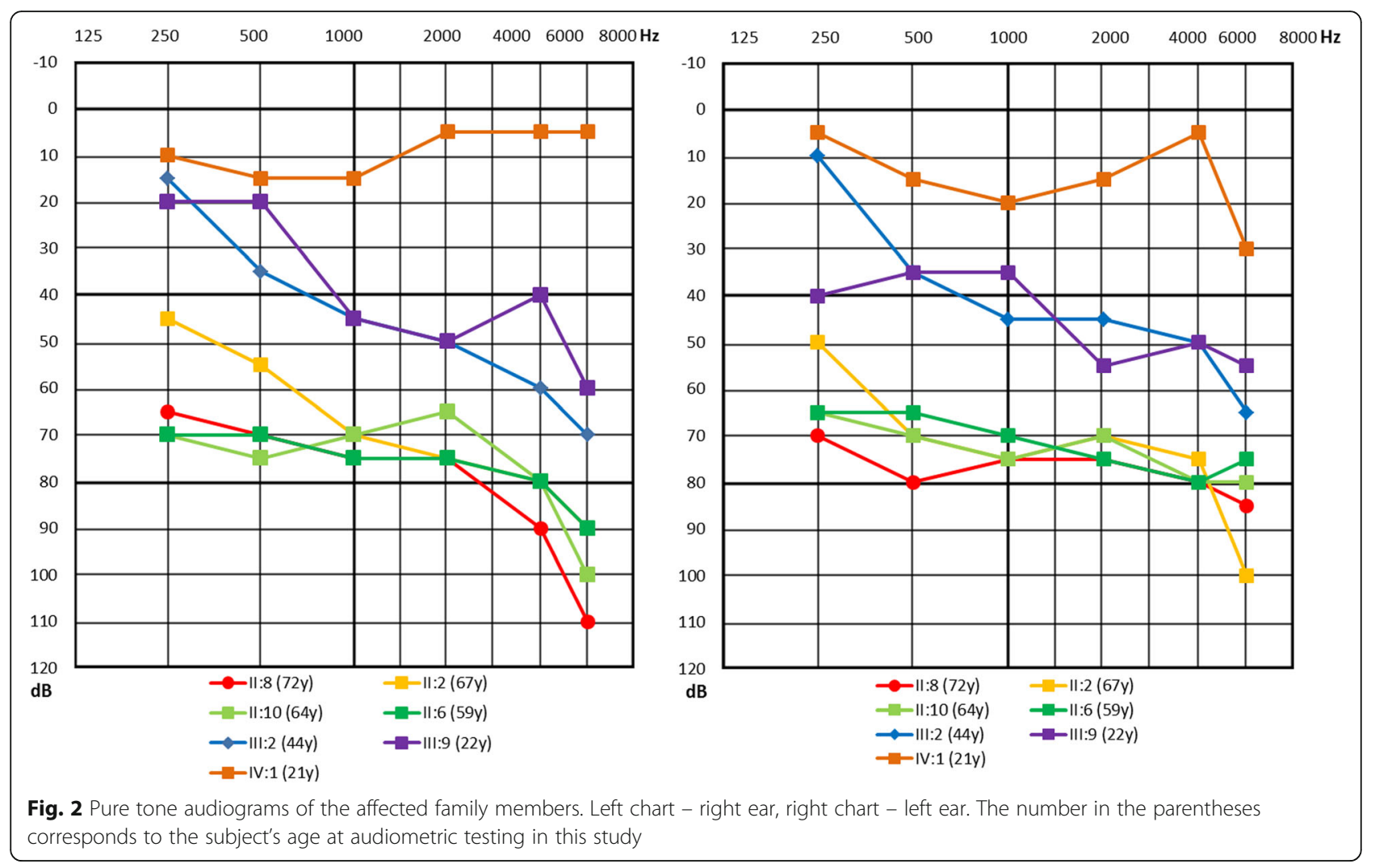

of heterozygous vs. non-reference homozygous genotype ratios were within recommended boundaries for WES data $[24,25]$. Of those, 482 variants were novel and 1348 variants were present in at least one SNP polymorphism database (dbSNP, ESP, ExAC) with minor allele frequency (MAF) less than 1\%. Finally, 19 rare/novel variants were found inside regions of 91 genes which had been associated with NSNHL before.

Ultimately, only 5 from 19 variants left by upstream analysis were localized within coding regions of NSNHL genes and only 3 variants were predicted to result in a change of amino acid sequence (Table 2). The only novel variant was EYA4: c.804G > C transversion, which in respect to the amino acids is inferred to replace the glutamine with histidine residue at position 268 in the eyes absent 4 protein. However, since the changed nucleotide is the last base of EYA4 exon 10, and similar variants surrounding splice sites in other genes can induce changes in mRNA splicing $[26,27]$, additional analysis using in-silico splice site prediction tools was performed.

The Human Splicing Finder algorithm score was near the threshold value for exon being recognized by the spliceosome, whereas MaxEntScan with NNSplice indicated that the mutated sequence is not likely to be functional splice donor site (Table 3). In combination, these scores suggested a high likelihood of splicing modification with resulting deleterious impact on protein sequence.
Presence of the c.804G $>\mathrm{C}$ variant in proband's DNA and its heterozygous genotype were confirmed by Sanger sequencing (Fig. 4). Additionally, DNA from all available affected and unaffected family members $(n=12)$ was investigated by cosegregation of the variant with hearing loss. Together 6 relatives of the proband were shown to have the EYA4 c.804G > C variant, all of them diagnosed with bilateral hearing loss, except individual IV:1, the youngest mutation carrier (21 years), who had yet normal hearing based on pure tone thresholds (Fig. 2). This variant was not present in the DNA of unaffected family members older than 30 years.

\section{Functional evaluation of the variant effect on splicing}

The effect of the c.804G $>\mathrm{C}$ variant on splicing was tested using minigene assay. The results showed that the wild type exon was correctly incorporated in $89 \%$ of transcripts, while the exon carrying the c.804G $>$ C variant failed to be retained in the mature transcript and was cut out during splicing (Fig. 5).

\section{Discussion \& Conclusions}

In the present study, we report a four-generation Slovak family in which postlingual nonsyndromic autosomal dominant SNHL segregates with the c.804G > C mutation in EYA4 discovered using whole exome sequencing approach. The mutation is located at the last base 


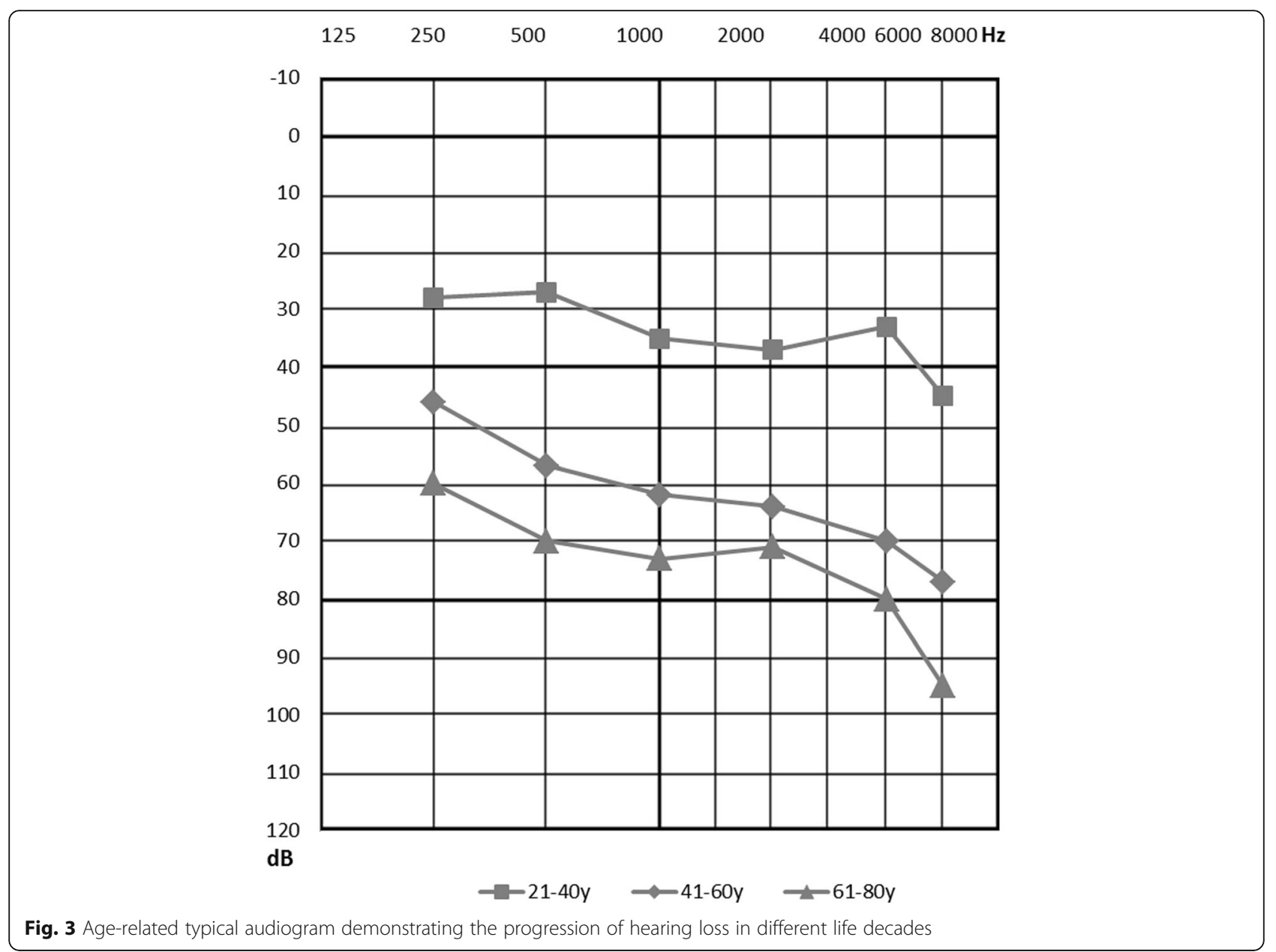

Table 1 Summary of whole exome sequencing and variant analysis

\begin{tabular}{ll}
\hline Summary of whole exome sequencing data & \\
\hline Subject & III:2 \\
\hline Sequencing, read alignment and coverage & \\
Uniquely mapped reads with MAPQ > = 30 [N] & $558,548,129$ \\
Fraction of targets covered $>=5 \times[\%]$ & 98.35 \\
Fraction of targets covered $>=20 x[\%]$ & 93.45 \\
Overall mean sequencing depth [x] & 162.22 \\
Variant calling & \\
Total identified variants [N] & 46,457 \\
Known variants with MAF < 0.01 (dbSNP,ESP,ExAC) [N] & 1348 \\
Novel variants [N] & 482 \\
Heterozygous/non-reference homozygous ratio & 1.64 \\
Transition/transversion ratio & 2.65 \\
\hline
\end{tabular}

position of the exon 10. To the best of our knowledge, this is the first point mutation localized in exon 10 and the first known case of EYA4 gene associated with SNHL in the Slavic Caucasian population.

Nucleotide substitutions affecting the last base pair of exon should be regarded as a rare event of which the effect is difficult to predict. At least 10 similar nucleotide changes have been shown to cause abnormal mRNA splicing in mammalian genes [28]. In-silico analysis using state-of-the-art prediction algorithms suggests that the mutation weakens splice donor site of intron 10. This may lead to complete or partial skipping of the exon 10, or to the activation of a cryptic splice donor site. As it is known that EYA4 is not expressed in blood [29], we tried to amplify EYA4 by RT-PCR from a urine sample from proband as well as from healthy control to determine the exact impact of the mutation of the last exonic nucleotide on mRNA splicing. However, we did not detect any EYA4 transcripts in the urine sample. Therefore, we applied the mini-gene assay to test the functionality of the exon 10 mutated splice site. Our findings confirmed the in-silico predictions and showed that the 
Table 2 Rare and novel variants present in coding regions of 91 genes associated with non-syndromic hereditary hearing loss

\begin{tabular}{|c|c|c|c|c|c|c|c|c|c|c|}
\hline \multicolumn{11}{|c|}{ Rare and novel variants present in panel of NSNHL genes in proband } \\
\hline Gene & Nucleotide & Exon & rsID & Sequence impact & $\begin{array}{l}\text { CADD } \\
\text { scaled }\end{array}$ & PolyPhen & SIFT & $\begin{array}{l}\text { MAF } \\
1000 \mathrm{G} \text { all }\end{array}$ & $\begin{array}{l}\text { MAF } \\
\text { ESP all }\end{array}$ & $\begin{array}{l}\text { MAF } \\
\text { EXAC all }\end{array}$ \\
\hline $\begin{array}{l}\text { USH2A } \\
\text { NM_206933.2 }\end{array}$ & $\begin{array}{l}\text { c.14074G > A } \\
\text { p.Gly4692Arg }\end{array}$ & 64 & rs45549044 & Missense & 19.61 & PD & $T$ & 0.002 & 0.0048 & 0.0048 \\
\hline $\begin{array}{l}\text { EYA4 } \\
\text { NM_004100.4 }\end{array}$ & $\begin{array}{l}\text { c. } 804 G>C \\
\text { p.Gln268His }\end{array}$ & 10 & N/A & $\begin{array}{l}\text { Missense, Splicing } \\
\text { region variant }\end{array}$ & 25 & PD & $\mathrm{D}$ & N/A & N/A & N/A \\
\hline $\begin{array}{l}\text { MCPH1 } \\
\text { NM_024596.4 }\end{array}$ & $\begin{array}{l}\text { c. } 2180 C>T \\
\text { p.Pro727Leu }\end{array}$ & 12 & rs199861426 & Missense & 13.36 & B & $\mathrm{D}$ & N/A & 0.0008 & 0.0011 \\
\hline $\begin{array}{l}\text { MYO7A } \\
\text { NM_000260.3 }\end{array}$ & $\begin{array}{l}\text { c.5598C > A } \\
\text { p.Leu1866= }\end{array}$ & 40 & rs111033504 & Synonymous & 3.5 & N/A & N/A & 0.002 & N/A & 0.0022 \\
\hline $\begin{array}{l}\text { OTOA } \\
\text { NM_144672.3 }\end{array}$ & $\begin{array}{l}\text { c. } 2229 \text { C }>T \\
\text { p.Ala743 }=\end{array}$ & 20 & rs461179 & Synonymous & 1.96 & N/A & N/A & N/A & N/A & 0.0094 \\
\hline
\end{tabular}

$1000 G 1000$ Genomes project, ESP Exome sequencing project, ExAC Exome Aggregation Consortium, MAF Minor allele frequency, PD probably damaging, $B$ benign, $T$ tolerated, $D$ deleterious

c.804G > C mutation compromises donor site functionality and causes exon 10 skipping in vitro. Exon 10 skipping in the EYA4 mRNA splicing would result in frame-shift p.(Ser243Leufs ${ }^{* 29)}$ that introduces premature termination codon (PTC) and would thus lead to nonsense-mediated mRNA decay (NMD). However, we cannot exclude the formation of other mutant transcripts, as disruption of one splice site can influence also splicing of other adjacent exons and this we have not tested.

To date, 19 pathogenic or probably pathogenic EYA4 variants associated with non-syndromic autosomal dominant SNHL (DFNA10) have been reported in about 20 families. Moreover, a large deletion c.581_804del was associated with SNHL and dilation cardiomyopathy resulting in risk of premature death [30, 31]. Genetic and clinical characteristics of known EYA4 mutations are summarized in Table 4. Similar syndromic phenotype (hearing loss and cardiac malformation) plus microcephaly and mental retardation were observed in $9 \mathrm{Mb}$ deletion 6q23.2-24.1 which also disrupts EYA4 gene [32].

The most frequent type of mutations observed so far in EYA4 were frameshifts and nonsense mutations, both leading to the introduction of a premature termination codon (PTC) into mRNA sequence. Presence of the PTC in the mRNA molecule makes the molecule a potential subject of NMD pathway that selectively degrades transcripts carrying PTCs which are 50-55 nucleotides

Table 3 Results from in-silico analysis of the splice donor site of the intron 10. Scores for wild-type and c.804G > C sequences are presented

\begin{tabular}{llll}
\hline \multicolumn{4}{l}{ Splice site prediction for splice donor variant c.804G > C } \\
\hline Program & wt score & c.804G > C score & threshold value \\
\hline MaxEntScan & 8.73 & -4.91 & 3 \\
HSF 3.0 & 77.1 & 66.08 & 65 \\
NNSplice 0.9 & 0.87 & splice site not recognized & 0.4 \\
\hline
\end{tabular}

A sequence is predicted to be a functional splice site if the score is higher than the given threshold value upstream from the last exon-exon junction [33]. In result, mRNA molecule transcribed from the mutated allele would be completely degraded. In the remaining families, nonsynonymous mutations leading to substitutions of highly conserved amino acid residues were identified (Table 4). The prevalence of EYA4/DFNA10 related deafness is not known and it was only detected in Caucasian and East Asian population to date. The only relevant data on epidemiology is from Korea, where the prevalence of EYA4 among nonsyndromic ADSNHL is estimated at $7.4 \%$ [34]. In our series, EYA4 mutation was identified in $5.56 \%(1 / 18)$ of probands with nonsyndromic ADSNHL analyzed by next-generation sequencing.

The exact molecular pathomechanism of hearing impairment associated with mutations in EYA4 has not been determined yet, but it may result from lowered gene dosage or reduced protein activity. The EYA proteins are transcriptional coactivators that interact with the transcription factors SIX and DACH but lack a DNA-binding domain [35]. EYA4 acts as a histone phosphatase and promotes efficient DNA repair. Studies of expression in rodent inner ear suggest developmental role during maturation of the inner ear as well as survival role in the mature system [36]. One of the possible pathomechanisms involved in hearing loss development due to EYA4 mutations may be the impaired regulation of $\mathrm{Na}+/ \mathrm{K}+$-ATPase by altered expression of its $\beta 2 \mathrm{~b}$ subunit as demonstrated in zebrafish model [37].

Hearing loss in the investigated family had postlingual onset from 10 to 40 years, which corresponds to the onset range (6-40 years) reported in the literature [38]. This relatively broad interval was observed even among the same mutation carriers and members of the same families and is not yet explained. Environmental or intrinsic factors, such as chronic noise exposure or other genetic factors may play a role. However, self-reported hearing loss onset used in this and previous studies is also a matter of subjective disability evaluation, which 


\section{EYA4-NM_004100.4}

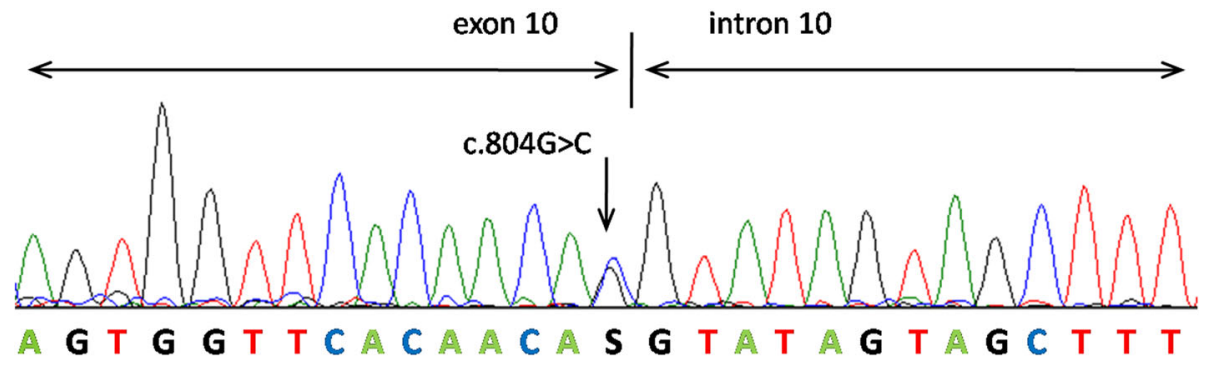

Fig. $\mathbf{4}$ Validation of candidate mutation by Sanger sequencing. The sequence of splice donor site of exon 10 presenting heterozygous mutation c.804G > C in an affected family member (III.2). The arrow indicates the site of mutation

may vary among affected subjects. Especially in mild degree cases with slow progression, the hearing loss may remain unnoticed for a longer period of time. Therefore, prospective audiological assessment of yet asymptomatic mutation carriers will be required in the future to obtain more precise data. The audiogram shape and degree of hearing loss in EYA4 deafness are variable. Most often it is described as mid-frequency hearing loss ("cookie bite" audiogram) of a mild to moderate degree at the time of onset. Subsequent hearing deterioration also affects the high frequencies resulting in the flat or down-sloping audiometric curve of a moderate to profound degree (Table 4). In our investigated family, the shape of audiogram was relatively constant (gently downsloping) since its onset. The severity of hearing loss based on pure tone average $(0.5-4 \mathrm{kHz})$ in the five subjects with deafness duration of $\geq 20$ years ranged from $43.75 \mathrm{~dB}$ to $77.5 \mathrm{~dB}$, not yet fulfilling the traditional criteria for cochlear implantation.
The effect of EYA4 truncating mutations on cardiac functions is often discussed due to the cardiomyopathy found in patients with large deletions comprising the variable domain $[7,30,32]$. However, despite the process of NMD is known now for almost four decades and was accepted to be the consequence of mutations introducing PTC [39], only Pfister et al. [40] suggested that the frameshift mutations in EYA4 will cause NMD. In such a case it is irrelevant to discuss the localization of the so-called truncating mutations in different EYA4 domains. We agree with this view, as all the patients with PTC share the same phenotype without cardiac symptoms similarly to the individuals with a missense mutation, which is also the case of patients studied in this report. All of them had normal morphology and function of the heart, without any signs of dilation cardiomyopathy. This would argue for the haploinsufficiency as the mechanism of this dominantly inherited hearing loss. Thus, it is more probable, that the reported

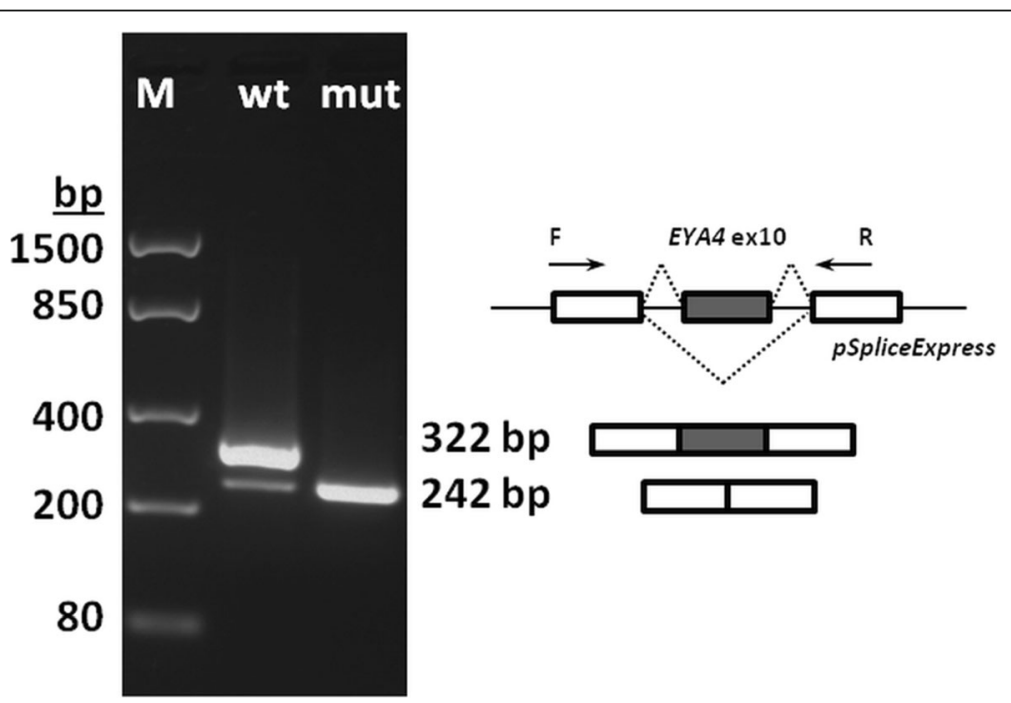

Fig. 5 Mini-gene assay results. Wild-type EYA4 exon 10 (wt) is incorporated into the mature transcript, exon 10 with c.804G > C mutation (mut) is spliced out 


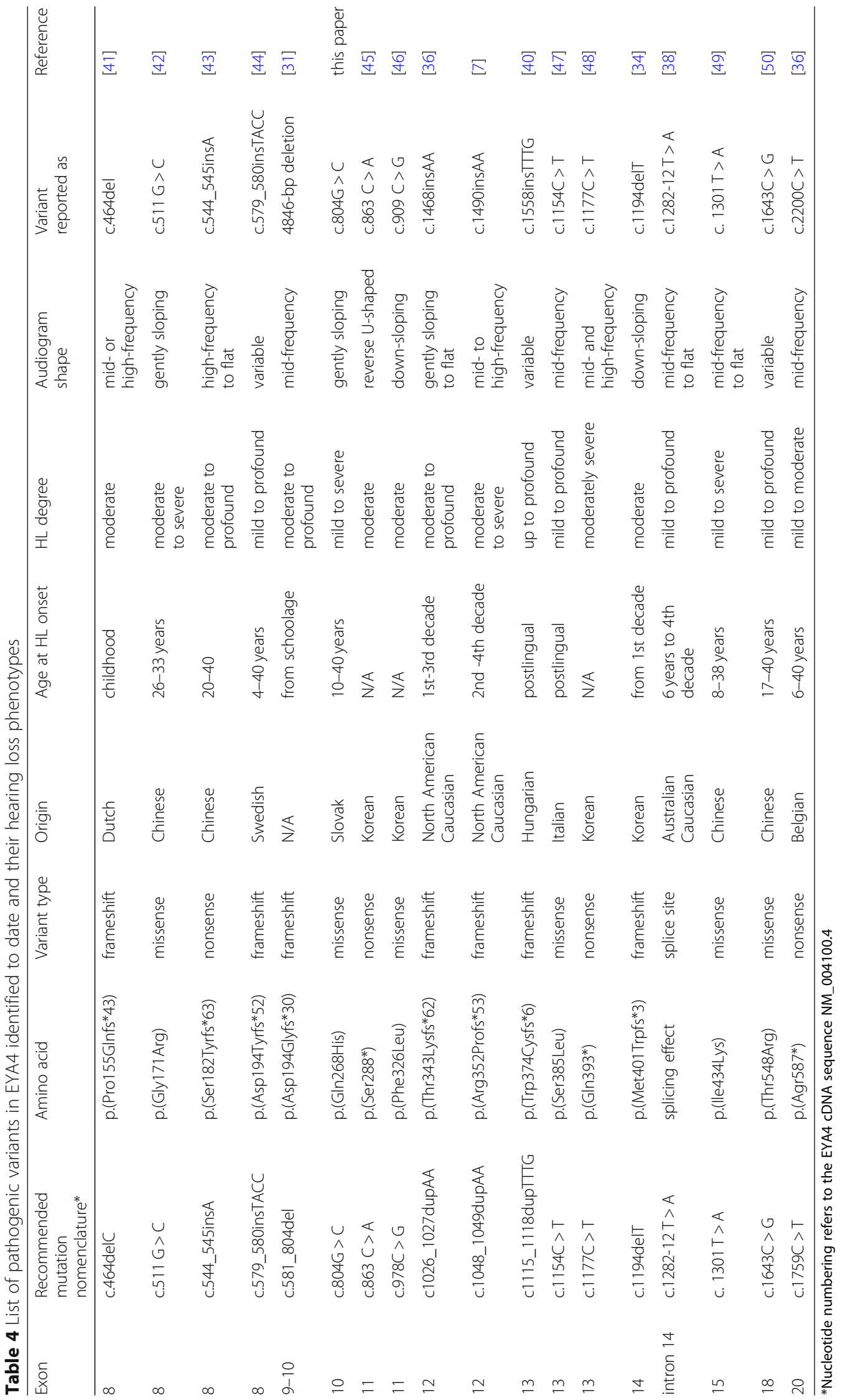


cardiomyopathy was caused by other genetic factors present in the large deleted regions or created by the event of deletion. The definitive answer could be attained by estimating the level of the EYA4 mRNA transcripts in patient's cells, but EYA4 is not expressed in blood leukocytes making this test inaccessible without a biopsy.

In conclusion, a novel EYA4 mutation, c.804G > C (p.Gln268His), was identified in a Slovak nonsyndromic ADNSHL family using WES and Sanger sequencing. This variant represents a nucleotide change at the last base pair of exon 10. We demonstrate in vitro that c.804G $>\mathrm{C}$ leads to exon 10 skipping resulting in frame-shift that introduces premature termination codon. To the best of our knowledge, this is the first EYA4 mutation associated with ADSNHL in the Slavic Caucasian population. Regarding the auditory phenotype, most of the variability concerned the onset of hearing loss, whereas the shape of the audiometric curve and progression after clinical manifestation were relatively uniform.

\section{Abbreviations}

ABR: Auditory brainstem responses; ADSNHL: Autosomal dominant sensorineural hearing loss; ARTA: Age-related typical audiogram; $\mathrm{CT}$ : Computer tomography; DFNA: Deafness nonsyndromic autosomal dominant; DFNB: Deafness nonsyndromic autosomal recessive; ECG: Electrocardiogram; EYA4: Eyes Absent Homolog 4; eya-HR: eya homologous region; eya-VR: eya variable region; MAF: Minor allele frequency; MRI: Magnetic resonance imaging; NMD: Nonsense-mediated mRNA decay; NSNHL: Nonsyndromic sensorineural hearing loss; PST: Proline-serinethreonine; PTC: Premature termination codon; SNHL: Sensorineural hearing loss; SNP: Single nucleotide polymorphism; VEMPs: Vestibular evoked myogenic potentials; WES: Whole exome sequencing

\author{
Acknowledgments \\ We would like to thank Andrea Markova, M.D. for referring the family \\ described in the paper.
}

\section{Funding}

This work was funded by grants APW 15-0067 and VEGA 1/0214/16.

\section{Availability of data and materials}

All data generated or analysed during this study are included in this published article.

\section{Authors' contributions}

LV and DG designed the study. LV, DD, and MS wrote the manuscript. LV and LD collected material and performed the clinical part of the study. DD, MS, ZS, and IM performed the laboratory analyses. MP and DG supervised the study and revised the manuscript. Each listed author qualifies for authorship according to the ICMJE guideline criteria and all authors have read and approved the manuscript.

\section{Ethics approval and consent to participate}

All participants or their legal representatives signed informed consent and the study was approved by the Ethics Committee of University Hospital in Bratislava.

\section{Consent for publication}

Written informed consent for publication of their clinical details and/or clinical images was obtained from the patient/parent/guardian/ relative of the patient. A copy of the consent form is available for review by the Editor of this journal.

\section{Competing interests}

The authors declare that they have no competing interests.

\section{Publisher's Note}

Springer Nature remains neutral with regard to jurisdictional claims in published maps and institutional affiliations.

\section{Author details}

${ }^{1}$ Department of Otorhinolaryngology - Head and Neck Surgery, Faculty of Medicine and University Hospital, Comenius University, Bratislava, Slovakia.

${ }^{2}$ Diabgene Laboratory, Biomedical Research Center, University Science Park for Biomedicine, Slovak Academy of Sciences, Bratislava, Slovakia.

Received: 14 December 2018 Accepted: 15 April 2019

Published online: 17 May 2019

\section{References}

1. Hereditary Hearing Loss Homepage [http://hereditaryhearingloss.org].

2. Walsh T, Pierce SB, Lenz DR, Brownstein Z, Dagan-Rosenfeld O, Shahin H, Roeb W, McCarthy S, Nord AS, Gordon CR, et al. Genomic duplication and overexpression of TJP2/ZO-2 leads to altered expression of apoptosis genes in progressive nonsyndromic hearing loss DFNA51. Am J Hum Genet. 2010; 87(1):101-9.

3. Pauw RJ, Huygen PL, Colditz GM, Cremers CW. Phenotype analysis of an Australian DFNA9 family with the 1109N COCH mutation. Ann Otol Rhinol Laryngol. 2011;120(6):414-21

4. Toriello HV, Smith SD. Hereditary Hearing Loss and Its Syndromes. Oxford: Oxford University Press; 2013

5. Tadjuidje E, Hegde RS. The eyes absent proteins in development and disease. Cell Mol Life Sci. 2013;70(11):1897-913.

6. Borsani G, DeGrandi A, Ballabio A, Bulfone A, Bernard L, Banfi S, Gattuso C, Mariani M, Dixon M, Donnai D, et al. EYA4, a novel vertebrate gene related to Drosophila eyes absent. Hum Mol Genet. 1999;8(1):11-23.

7. Makishima T, Madeo AC, Brewer CC, Zalewski CK, Butman JA, Sachdev V, Arai AE, Holbrook BM, Rosing DR, Griffith AJ. Nonsyndromic hearing loss DFNA10 and a novel mutation of EYA4: evidence for correlation of normal cardiac phenotype with truncating mutations of the EYA domain. Am J Med Genet A. 2007;143A(14):1592-8.

8. Tan A, Abecasis GR, Kang HM. Unified representation of genetic variants. Bioinformatics. 2015:31(13):2202-4.

9. McLaren W, Gil L, Hunt SE, Riat HS, Ritchie GR, Thormann A, Flicek P, Cunningham F. The Ensembl variant effect predictor. Genome Biol. 2016; 17(1):122.

10. Paila U, Chapman BA, Kirchner R, Quinlan AR. GEMINI: integrative exploration of genetic variation and genome annotations. PLoS Comput Biol. 2013;9(7):e1003153.

11. Sherry ST, Ward MH, Kholodov M, Baker J, Phan L, Smigielski EM, Sirotkin K. dbSNP: the NCBI database of genetic variation. Nucleic Acids Res. 2001; 29(1):308-11.

12. Consortium EP. An integrated encyclopedia of DNA elements in the human genome. Nature. 2012;489(7414):57-74.

13. Genomes Project C, Abecasis GR, Auton A, Brooks LD, DePristo MA, Durbin RM Handsaker RE, Kang HM, Marth GT, McVean GA. An integrated map of genetic variation from 1,092 human genomes. Nature. 2012;491(7422):56-65.

14. Choi Y, Sims GE, Murphy S, Miller JR, Chan AP. Predicting the functional effect of amino acid substitutions and indels. PLoS One. 2012;7(10):e46688.

15. Lek M, Karczewski K, Minikel EV, Samocha KE, Banks E, Fennell T, O'DonnellLuria AH, Ware JS, Hill AJ, Cummings BB, et al. Analysis of protein-coding genetic variation in 60,706 humans. Nature. 2016;536(7616):285-91.

16. Kircher M, Witten DM, Jain P, O'Roak BJ, Cooper GM, Shendure J. A general framework for estimating the relative pathogenicity of human genetic variants. Nat Genet. 2014:46(3):310-5.

17. Adzhubei IA, Schmidt S, Peshkin L, Ramensky VE, Gerasimova A, Bork P, Kondrashov AS, Sunyaev SR. A method and server for predicting damaging missense mutations. Nat Methods. 2010;7(4):248-9.

18. Kumar P, Henikoff S, Ng PC. Predicting the effects of coding nonsynonymous variants on protein function using the SIFT algorithm. Nat Protoc. 2009;4(7):1073-81.

19. Yeo G, Burge CB. Maximum entropy modeling of short sequence motifs with applications to RNA splicing signals. J Comput Biol. 2004;1 1(2-3):377-94. 
20. Desmet FO, Hamroun D, Lalande M, Collod-Beroud G, Claustres M, Beroud C. Human splicing finder: an online bioinformatics tool to predict splicing signals. Nucleic Acids Res. 2009;37(9):e67.

21. Reese MG, Eeckman FH, Kulp D, Haussler D. Improved splice site detection in genie. J Comput Biol. 1997;4(3):311-23.

22. Kishore S, Khanna A, Stamm S. Rapid generation of splicing reporters with pSpliceExpress. Gene. 2008;427(1-2):104-10.

23. Schneider CA, Rasband WS, Eliceiri KW. NIH image to ImageJ: 25 years of image analysis. Nat Methods. 2012;9(7):671-5.

24. Guo Y, Ye F, Sheng Q, Clark T, Samuels DC. Three-stage quality control strategies for DNA re-sequencing data. Brief Bioinform. 2014;15(6):879-89.

25. Wang J, Raskin L, Samuels DC, Shyr Y, Guo Y. Genome measures used for quality control are dependent on gene function and ancestry. Bioinformatics. 2015;31(3):318-23.

26. Montera M, Piaggio F, Marchese C, Gismondi V, Stella A, Resta N, Varesco L, Guanti G, Mareni C. A silent mutation in exon 14 of the APC gene is associated with exon skipping in a FAP family. J Med Genet. 2001;38(12):863-7.

27. Najm J, Horn D, Wimplinger I, Golden JA, Chizhikov W, Sudi J, Christian SL, Ullmann R, Kuechler A, Haas CA, et al. Mutations of CASK cause an X-linked brain malformation phenotype with microcephaly and hypoplasia of the brainstem and cerebellum. Nat Genet. 2008;40(9):1065-7.

28. Krawczak M, Reiss J, Cooper DN. The mutational spectrum of single basepair substitutions in mRNA splice junctions of human genes: causes and consequences. Hum Genet. 1992;90(1-2):41-54.

29. Li H, Diao TY, Zhou ZY, Yang FY, Ma Q, Li QH. Relationship between the expression of hTERT and EYA4 mRNA in peripheral blood mononuclear cells with the progressive stages of carcinogenesis of the esophagus. J Exp Clin Cancer Res. 2009:28:145.

30. Schonberger J, Levy H, Grunig E, Sangwatanaroj S, Fatkin D, MacRae C, Stacker H, Halpin C, Eavey R, Philbin EF, et al. Dilated cardiomyopathy and sensorineural hearing loss: a heritable syndrome that maps to 6q23-24. Circulation. 2000;101(15):1812-8.

31. Schonberger J, Wang L, Shin JT, Kim SD, Depreux FF, Zhu H, Zon L, Pizard A, Kim JB, Macrae CA, et al. Mutation in the transcriptional coactivator EYA4 causes dilated cardiomyopathy and sensorineural hearing loss. Nat Genet. 2005:37(4):418-22

32. Dutrannoy V, Klopocki E, Wei R, Bommer C, Mundlos S, Graul-Neumann LM, Trimborn M. De novo $9 \mathrm{Mb}$ deletion of $6 \mathrm{q} 23.2 \mathrm{q} 24.1$ disrupting the gene EYA4 in a patient with sensorineural hearing loss, cardiac malformation, and mental retardation. Eur J Med Genet. 2009;52(6):450-3.

33. Schoenberg DR, Maquat LE. Regulation of cytoplasmic mRNA decay. Nat Rev Genet. 2012;13(4):246-59.

34. Choi HS, Kim AR, Kim SH, Choi BY. Identification of a novel truncation mutation of EYA4 in moderate degree hearing loss by targeted exome sequencing. Eur Arch Otorhinolaryngol. 2016;273(5):1123-9.

35. Pignoni F, Hu B, Zavitz KH, Xiao J, Garrity PA, Zipursky SL. The eyespecification proteins so and Eya form a complex and regulate multiple steps in Drosophila eye development. Cell. 1997;91(7):881-91.

36. Wayne S, Robertson NG, DeClau F, Chen N, Verhoeven K, Prasad S, Tranebjarg L, Morton CC, Ryan AF, Van Camp G, et al. Mutations in the transcriptional activator EYA4 cause late-onset deafness at the DFNA10 locus. Hum Mol Genet. 2001;10(3):195-200.

37. Wang L, Sewell WF, Kim SD, Shin JT, MacRae CA, Zon LI, Seidman JG, Seidman CE. Eya4 regulation of $\mathrm{Na}+/ \mathrm{K}+-\mathrm{ATP}$ ase is required for sensory system development in zebrafish. Development. 2008;135(20):3425-34.

38. Hildebrand MS, Coman D, Yang T, Gardner RJ, Rose E, Smith RJ, Bahlo M, Dahl HH. A novel splice site mutation in EYA4 causes DFNA10 hearing loss. Am J Med Genet A. 2007;143A(14):1599-604.

39. Holbrook JA, Neu-Yilik G, Hentze MW, Kulozik AE. Nonsense-mediated decay approaches the clinic. Nat Genet. 2004;36(8):801-8.

40. Pfister M, Toth $T$, Thiele H, Haack B, Blin N, Zenner HP, Sziklai I, Nurnberg P, Kupka S. A 4-bp insertion in the eya-homologous region (eyaHR) of EYA4 causes hearing impairment in a Hungarian family linked to DFNA10. Mol Med. 2002:8(10):607-11.

41. van Beelen E, Oonk AM, Leijendeckers JM, Hoefsloot EH, Pennings RJ, Feenstra I, Dieker HJ, Huygen PL, Snik AF, Kremer H, et al. Audiometric characteristics of a Dutch DFNA10 family with mid-frequency hearing impairment. Ear Hear. 2016;37(1):103-11.

42. Liu F, Hu J, Xia W, Hao L, Ma J, Ma D, Ma Z. Exome sequencing identifies a mutation in EYA4 as a novel cause of autosomal dominant non-syndromic hearing loss. PLoS One. 2015;10(5):e0126602.
43. Huang A, Yuan Y, Liu Y, Zhu Q, Dai P. A novel EYA4 mutation causing hearing loss in a Chinese DFNA family and genotype-phenotype review of EYA4 in deafness. J Transl Med. 2015;13:154.

44. Frykholm C, Klar J, Arnesson H, Rehnman AC, Lodahl M, Weden U, Dahl N, Tranebjaerg $L$, Rendtorff ND. Phenotypic variability in a seven-generation Swedish family segregating autosomal dominant hearing impairment due to a novel EYA4 frameshift mutation. Gene. 2015;563(1):10-6.

45. Baek Jl, Oh SK, Kim DB, Choi SY, Kim UK, Lee KY, Lee SH. Targeted massive parallel sequencing: the effective detection of novel causative mutations associated with hearing loss in small families. Orphanet J Rare Dis. 2012;7:60.

46. Choi BY, Park G, Gim J, Kim AR, Kim BJ, Kim HS, Park JH, Park T, Oh SH, Han $\mathrm{KH}$, et al. Diagnostic application of targeted resequencing for familial nonsyndromic hearing loss. PLoS One. 2013;8(8):e68692.

47. Cesca F, Bettella E, Polli R, Cama E, Scimemi P, Santarelli R, Murgia A. A novel mutation of the EYA4 gene associated with post-lingual hearing loss in a proband is co-segregating with a novel PAX3 mutation in two congenitally deaf family members. Int J Pediatr Otorhinolaryngol. 2018;104:88-93.

48. Kim YR, Kim MA, Sagong B, Bae SH, Lee HJ, Kim HJ, Choi JY, Lee KY, Kim UK. Evaluation of the contribution of the EYA4 and GRHL2 genes in Korean patients with autosomal dominant non-syndromic hearing loss. PLoS One. 2015;10(3):e0119443

49. Tan M, Shen X, Yao J, Wei Q, Lu Y, Cao X, Xing G. Identification of I411K, a novel missense EYA4 mutation causing autosomal dominant nonsyndromic hearing loss. Int J Mol Med. 2014;34(6):1467-72.

50. Sun Y, Zhang Z, Cheng J, Lu Y, Yang CL, Luo YY, Yang G, Yang H, Zhu L, Zhou J, et al. A novel mutation of EYA4 in a large Chinese family with autosomal dominant middle-frequency sensorineural hearing loss by targeted exome sequencing. J Hum Genet. 2015;60(6):299-304.
Ready to submit your research? Choose BMC and benefit from:

- fast, convenient online submission

- thorough peer review by experienced researchers in your field

- rapid publication on acceptance

- support for research data, including large and complex data types

- gold Open Access which fosters wider collaboration and increased citations

- maximum visibility for your research: over $100 \mathrm{M}$ website views per year

At BMC, research is always in progress.

Learn more biomedcentral.com/submissions 